could be applied in all Government farms and plantations, but what of the many millions of acres outside? No doubt it would be the most obvious solution of many pests to have a season, like the frost of winter in the United States and in the northern tracts of India, that would kill the cotton plant and the pests as well, so that next year's sowings would stand a chance of being clean. But in many parts of the cotton area of India two cotton crops are taken off the fields every yearthe uppam and nadam of Madras, for example. Cotton may, in fact, be seen growing throughout the year in almost any province of India, one crop coming immediately after the other. The soil is often such that a good staple may be raised on one plot of land, and an inferior on another closely adjacent, and the seasons of their production often overlap. Obviously, while there could not be any compulsory orders that would deprive the individual of his rights, the persuasion of personal advantage, once established by the success of neighbouring large plantations, would in a few years secure all that could be desired.

The salvation of the position is thus the establishment of independent large cotton plantations, but the most serious difficulty is the discovery of the alternative crop or crops most convenient and profitable. It is not cotton growing only (like tea planting) that has to be faced, but systematic tropical agriculture with a full rotation of crops. This aspect of the problem the report has, of course, not dealt with, and has only general principles to offer.

The extension into new areas -more especially lands with rich soils that need only enhanced schemes of water supply to bring them into bearing-is most fascinating, but, as the Indian Committee points out, better results may be looked for from an increase in the average annual yield than from new areas. That view is certainly correct, and should be faced by some practical scheme, and not by a panorama of committees.

GEORGE WATT.

\section{INDUSTRIAL AND MEDICAL RADIOLOGY.}

THE extent to which radiology has widened its scope during recent years was strikingly brought out by the exhibition of radiographs held very opportunely by the Röntgen Society at the Royal Photographic Society's galleries during January and February.

Radiology has usually been regarded as a special province of the physician and surgeon, which provides them with a routine means of quick and exact diagnosis. But radiology is spreading its NO. 2626 , VOL. IO4] wings into branches of activity far removed from medical endeavour, and the widening of its physical scope cannot fail to react beneticially on the older branch of the subject.

Simultaneously comes the awakening of the medical faculty generally to the importance and promise of physical methods and physical agencies as a means of progress in medical research. There is little doubt that within a short time every large and progressive hospital will have a physicist of standing on its staff; and in this connection we would congratulate the Middlesex Hospital on the good fortune which cnables it to establish what we believe is the first medical chair of physics in this country.

In particular, as regards radiology, the physicist will find work to hand in nearly every branch with which he comes in contact. Again, nearly all the

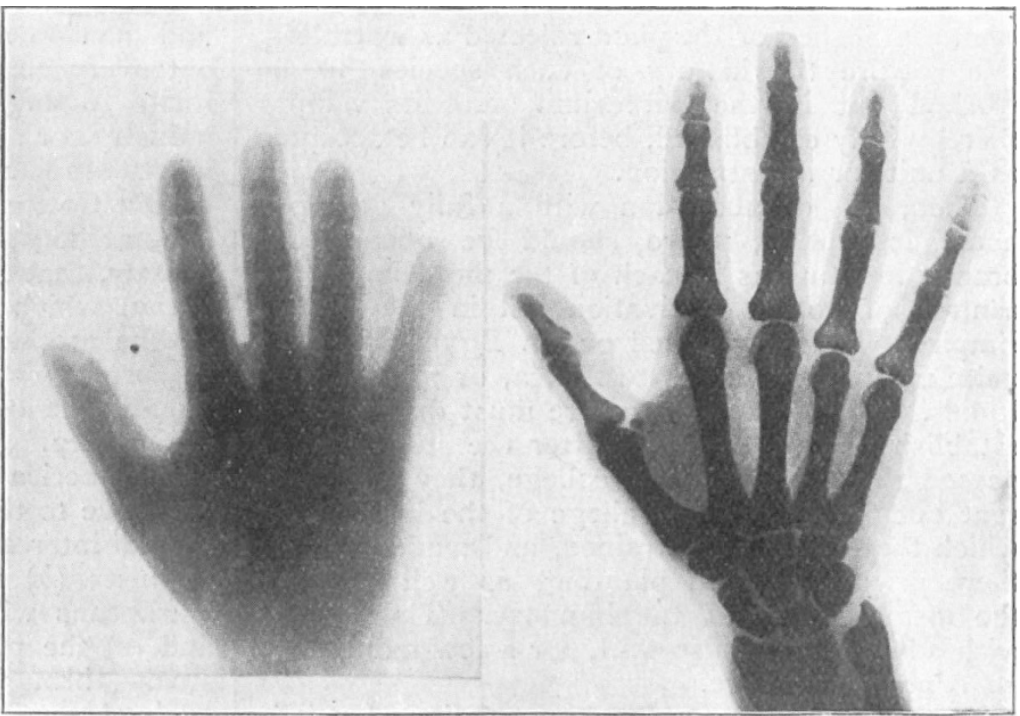

(a)

(b)

(Campbell Swinton.) problems of equipment and design are physical in character, and need physicists to tackle them, as America has already discovered to her profit. If the physicist can further obtain the co-operation of the electrical engineer, all-round improvements should speedily follow.

What of progress to date? The exhibition referred to here, although confined to radiographic prints, could very fairly be regarded as representative of present-day radiography, and as such it received generous approval from both the public and the Press. Some 200 prints were hung representing work by about thirty of the leading workers.

As a radiographer rarely takes his work beyond the negative stage, for the good reason that a print shows him no more, but usually rather less, than the negative, it was gratifying to find so high a pitch of photographic technique in the majority of the exhibits. On the other hand, few exhibitors had devoted much care or thought to the mounting 
of their work, a feature which a photographer would never be guilty of neglecting.

About half the exhibition was devoted to medical radiography, and the extraordinary progress that has been made since the discovery of the X-rays twenty-five years ago was strikingly brought out by the juxtaposition of two prints of the human hand (Fig. I), one taken in January, ı 896, by Campbell Swinton, with an exposure of twenty minutes, and the other in December, I9I9, by Knox, with a single-impulse flash occupying about $\mathrm{r} / \mathrm{I}$ oo sec. In the former the bones can be seen, though only blurred; in the latter (with I/I20,000 of the exposure) every detail is brilliantly portrayed. Knox further showed a fine series of flash radiographs of the chest (Fig. 2). Detection of stones in the kidney

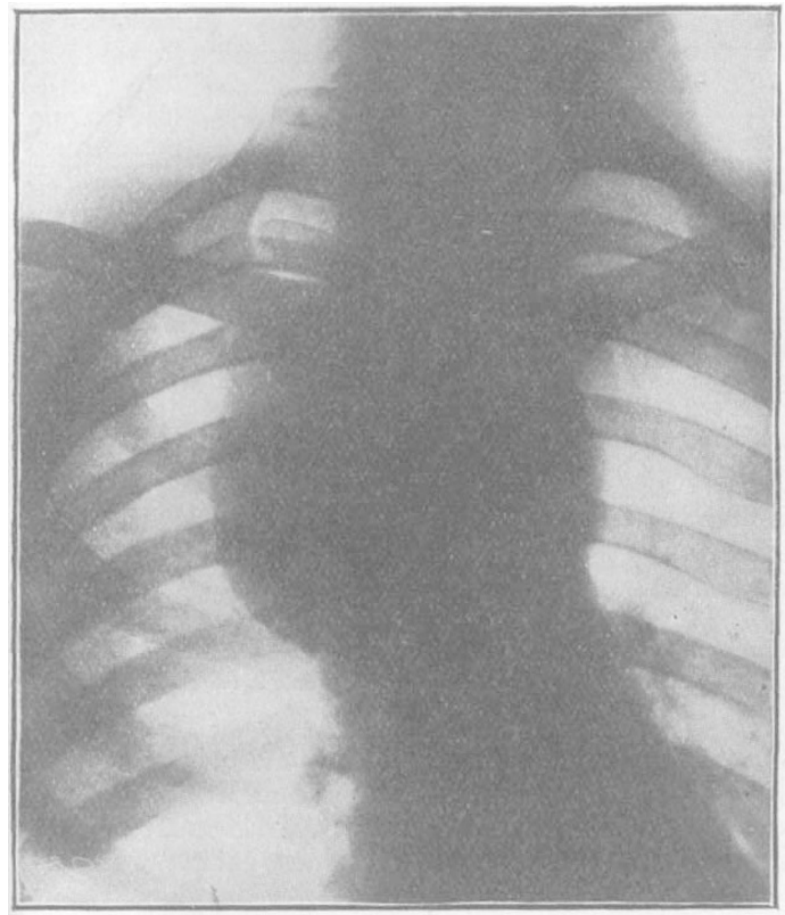

FIG. 2. - Flash radiograph of chest. (Knox.)

and bladder is now relatively straightforward work, as the constituent oxalates and phosphates are dense enough to cast good shadows. Until recently gall-stones (consisting chiefly of cholesterin) were deemed impossible of detection, but the radiographer acquires astounding skill in the interpretation of faint shadows, and both Thurstan Holland and Knox showed fine examples of success in diagnosing this troublesome complaint. Fig. 3 is an example of Thurstan Holland's work in barium-meal radiography.

A number of war radiographs were shown; one calling for comment was by Finzi of a bullet in the heart of a man who, it may be added, is still alive. Of interest also was the radiograph of the hand of an Egyptian mummy-a princess of the Second Dynasty (I 500 B.C.)---with a scarab ring on the third finger. (Evidently an X-ray equipment will have to be added to the Egyptologist's outtit !) NO. 2626 , VOL. IO4]
Some of the most attractive prints were those of shells and rare fossils taken by Rodman; the results reminded one irresistibly of the designs which the harmonograph traces out. Henri Beclere showed a new application of the rays in the radiographing of finger-prints. The skin is first rubbed over with red lead, and the radiograph shows the surface markings and openings of the cutaneous glands in so vivid a fashion as to suggest that the method would have advantages over that normally employed by the Criminal Investigation Department.

Several examples of negative prints on radio. bromide paper were exhibited, the most remarkable being that of the skeleton of a man. This radiograph, which was contained on a single sheet,

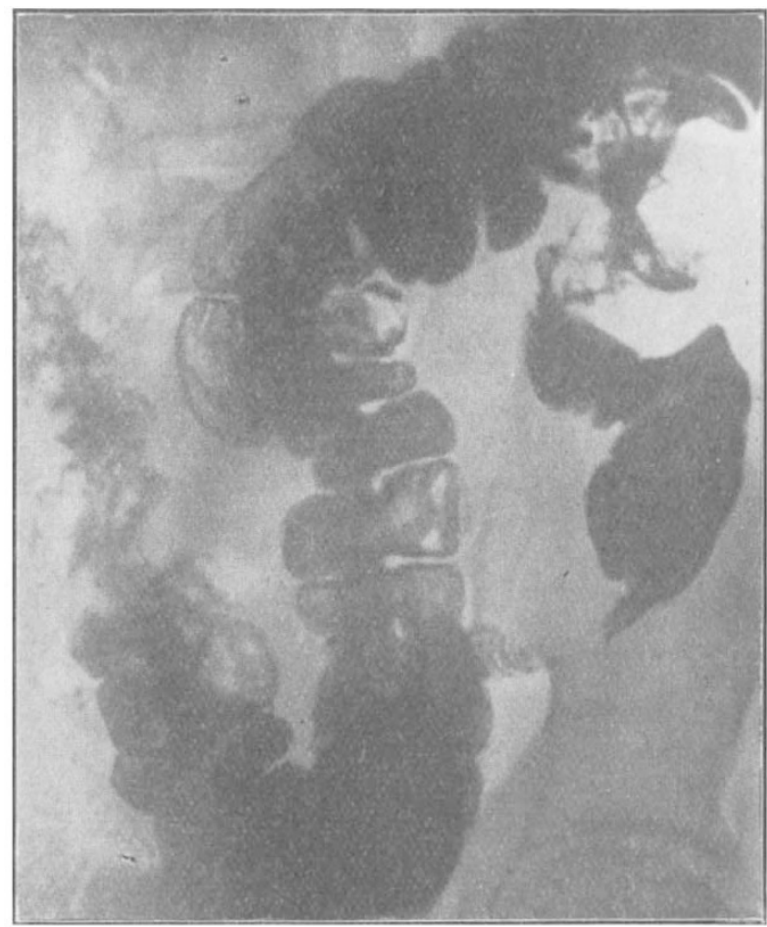

FIG. 3.- Right iliac fos:a after a barium meal, showing appendix, crecum ascending colon (with "filling defect" due to malignant growth), an transverse colon. (Thurstan Holland.)

$8 \mathrm{ft}$. by $4 \mathrm{ft}$, was taken by Forder with a Coolidge bulb working $8 \mathrm{ft}$. away.

The use of the $\mathrm{X}$-rays for revealing the interior of plant life is comparatively recent. Considerable differences exist in the mineral content and density, and hence in the transparency, of the different parts of a plant--root, stem, leaf, flower, fruit, seed, etc. It thus happens that even the most delicate structures of plants can be laid bare without tearing the plant to pieces in order to study it. Microscopic detail is, of course, not revealed. Long-waved X-rays are required for such work, of which Knox showed some good flower illustrations.

In the case of timber the different varieties absorb X-rays to different degrees. Peculiarities in the structure and course of the fibres (such as 
the contortions which produce "figure") are easily discerned. The denser heart wood is differentiated from the sap wood, the summer and spring growths of the annual rings are readily identified, and defects such as knots or grub-holes show up with astonishing clearness. Kaye and Knox showed some radiographs of aircraft timber and timber-structures taken during the war on behalf

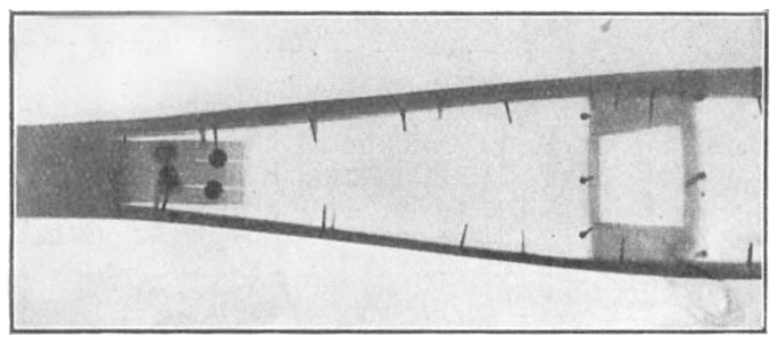

FIG. 4 - Radiograph of aeroplane hollow "box" strut, showing badly fitting internal end-block split by screws. (Kaye and Knox.)

of the Aeronautical Inspection Department (Fig. 4). The method is particularly useful in the case of hollow or laminated components, which cannot otherwise be thoroughly inspected except by destructive tests. Bad gluing, shoddy workmanship, and a variety of timber blemishes are detectable with ease, even on the fluorescent screen.

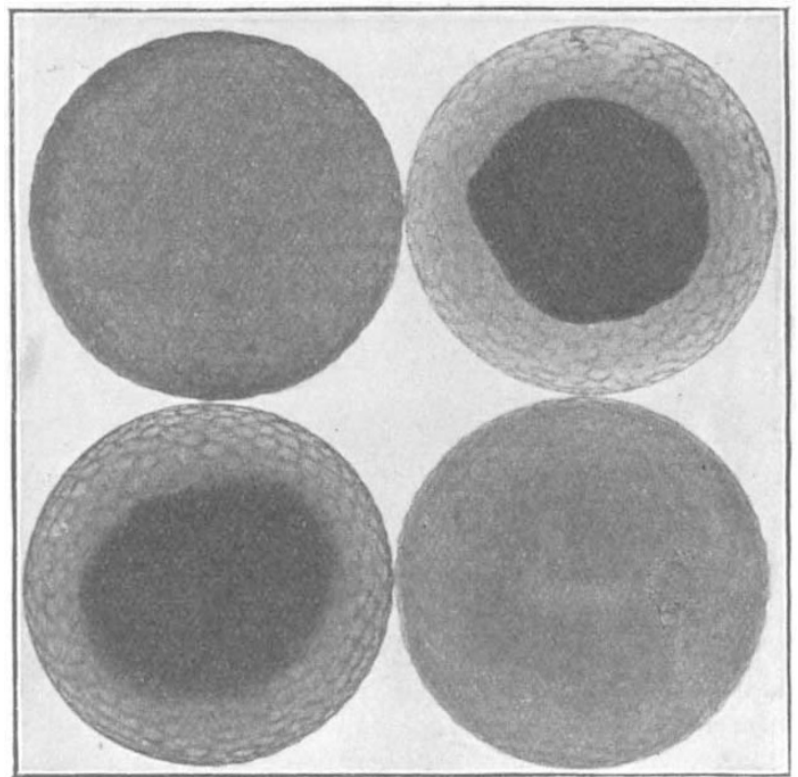

FIG. 5,-Golf balls, showing absence of core in "floaters" and irregular core in others. (Junic Research Laboratories.)

There appears to be considerable scope for this branch of radiography.

The radiographing of minerals is an easy means of detecting the presence of very dense elements such as uranium or tungsten. Pilon showed a good example of the method. The structure of golf balls is a somewhat unexpected subject (Batten). The "non-floaters" are wound on a NO. 2626, VOL. IO4] core of heavier rubber; some of the cores were spherical, but others were not-to the probable detriment of accuracy in long putting or driving. Undoubtedly the standardised championship balls of the future will have to satisfy an X-ray test!

A neat method of testing the electrically heated clothing of aeroplane pilots was shown by the Sunic Research Laboratories. The heating strip is sewn within the lining of the leather garment, and any break or kink in the element can easily be "spotted" on the fluorescent screen. The same laboratories showed radiographs of outer covers of motor and aeroplane tyres, and a variety of welds in metal tubes and plates, one of these of a steel plate $\frac{1}{2}$ in. thick being of particular excellence (Fig. 6). The Cox-Cavendish Co. showed a somewhat similar collection, and Chambers and Rankine displayed examples of their curious "diffraction" and multiple image $\mathrm{X}$-ray photography.

Among the most novel exhibits were those by Heilbron illustrating the X-ray examination of old paintings with the object of detecting alterations or additions made since the original work. Success in discovering any such falsifications would be

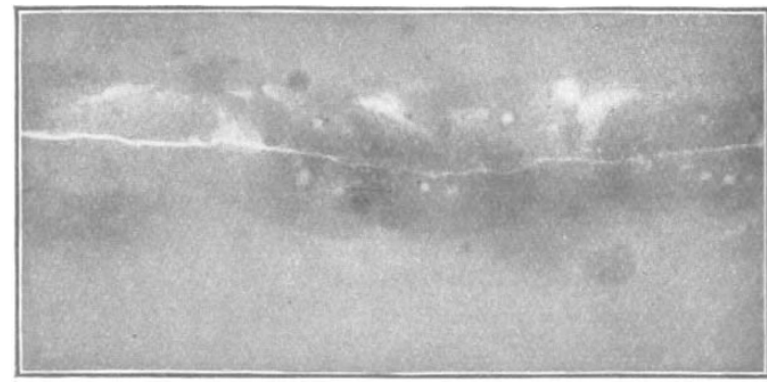

FiG. 6.-Bad weld in steel plates $\frac{1}{2}$ in. thick. (Sunic Research Laborator.es.)

possible only if the paint used in the original work were denser than that used in the additions. Some of the ancient pigments used by the masters are obscure in composition, but the blacks, for example, of a more modern day are largely carbon, and very transparent. Two examples of the method were shown, both by Dutch masters of the early sixteenth century. In one, a panel of the Madonna by St. Jans, the X-rays showed that the arms (which appear in a stiff and unnatural attitude) formerly held the Child, and in the other, the "Crucifixion" by Engelbrechtsz (Fig. 7), the radiograph revealed a number of "restorations," including the painting of the portrait of a former "donatrice" over the picture of a monk. As the Times remarked in a recent leader, this method of detecting the presence of later additions imposed on the work of the original artists suggests a great field for the re-investigation of palimpsests and ancient manuscripts hitherto regarded as carrying only their face value. Under the trivial inscriptions of medieval monks there may be revealed older matter of priceless worth. We commend the notion to the directors of the various art galleries and museums.

Space considerations have compelled a some- 
what invidious selection of exhibits for comment, and we have had to leave much interesting and clever work unnoticed. But, granting the scope and versatility of the attack, we venture to predict that the exhibition will be as nothing to a similar one held, say, in five or ten years' time. Great improvements are imperative, and will doubtless be forthcoming, in the means of registering X-rays. Photographic plates and fluorescent screens need to be improved out of recognition. A good explorer for use in radio-metallography could doubtless be evolved by means of the thermionic valve, as in wireless telegraphy.

With improved equipment radiology will acquire powers which will give it acknowledged status among the sciences, and medical radiology will find an unquestioned place in every medical curriculum. The diploma of medical radiology established last term by the University of Cambridge lative effort to succeed. The really remarkable thing about Peary is that the method by which he achieved success was practically independent of modern developments in the art of travel. Before very long the North Pole will be accessible by aircraft; it is possible that it might have been attainable years ago by a steamer in an exceptionally open season, but Peary reached the Pole without mechanical help, by the exercise of the powers of human mind and body alone; and had he been a contemporary of Hudson or of Davis there seems to be no reason why his genius could not have won success in the sixteenth or seventeenth century as well as in the twentieth.

Peary's professional training was that of a landsurveyor and civil engineer, and from early youth he was accustomed to find his way through unmapped solitudes and to survey routes hitherto untrodden. $\mathrm{He}$ was engaged, amongst other

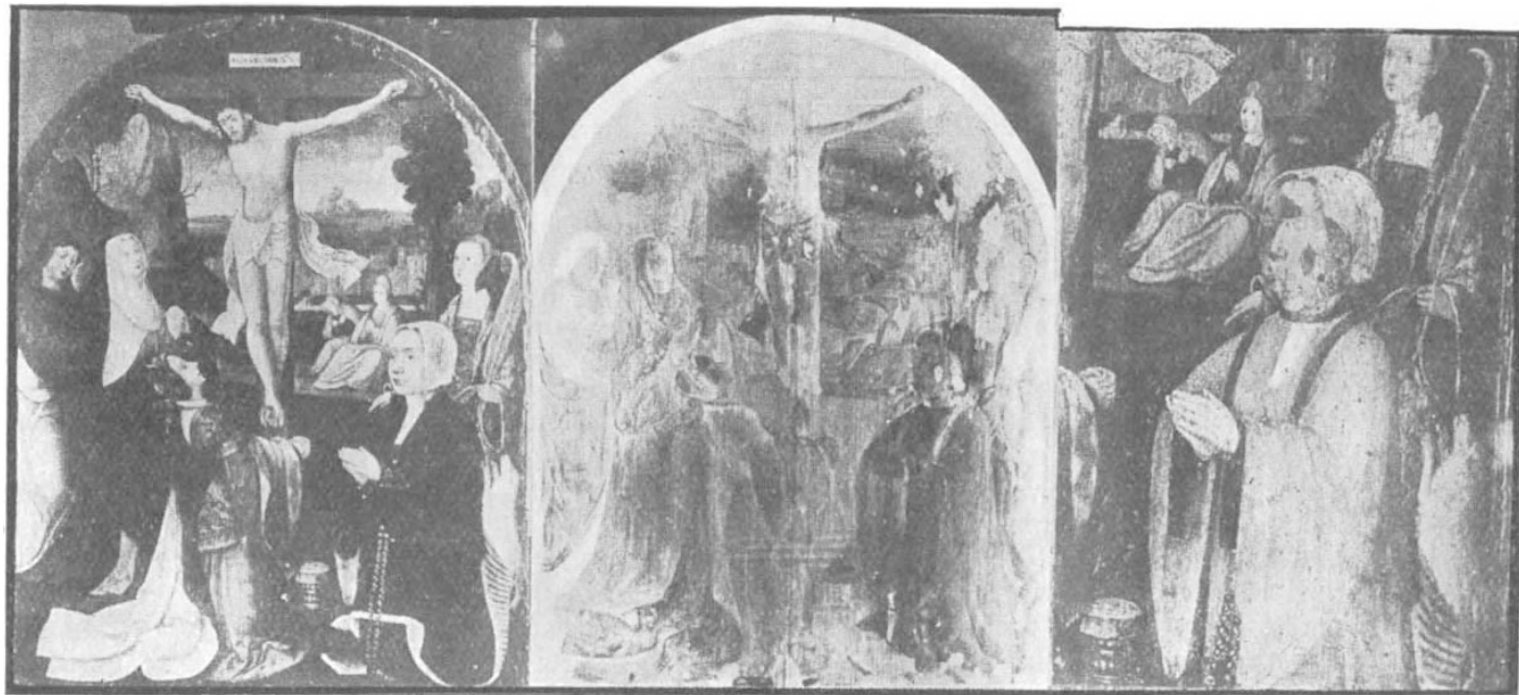

(a)

(b)

(c)

FIG. 7. -The "Crucifixion" by Cornelis Engelbrechtsz (c. 1500). (a) Natural photograph. (b) Radiograph showing monk in surplice and stole underlying portrait of "donatrice" on right (Heilbron). (c) Natural photograph taken during process of restoration, revealing monk.

is a first step. An even bigger one would be the setting up of an X-ray institute in London, which, properly staffed and equipped, would lead to incalculable progress. We understand that such an institute forms part of a forthcoming memorial scheme to the late Sir James Mackenzie Davidson, which we trust will command generous support.

G. W. C. KAYE.

\section{REAR-ADMIRAL R. E. PEARY, U.S.N.}

THE death of Rear-Admiral Peary at Washington on February 19, at the age of sixty-four, removes one of the most remarkable of modern explorers. It is not so much to the crowning achievement of his life in reaching the North Pole that Peary's claim to the respect of the geographical world is due as to the manner in which he persevered, in the face of almost overpowering difficulties, with very slender resources in a cumuNO. 2626 , VOL. IO4] things, on the survey of the abortive Nicaragua Canal after he had joined the civil engineeringbranch of the United States Navy, and his naval rank must not be taken to imply that he was in any sense a sailor. His official work lay in the construction of harbours and dockyards, and the world owes a debt to the enlightened chiefs of the United States Navy, who recognised that they were making a wise use of their powers in granting this born explorer unlimited leave for Arctic work.

Peary was led to visit Greenland for the first time in 1886 on account of his interest in Baron Nordenskiold's journey on the inland ice, and he returned from the trip determined to continue the exploration of the ice-cap in its least-known parts. In $189 \mathrm{r}-92$ he spent thirteen months in northern Greenland, establishing himself amongst the Etah Eskimo on Whale Sound, and making a I200mile journey with "dog-sledges to the north-eastern 